\title{
Grouping and Comparison of Container Substrates Based on Physical Properties Using Exploratory Multivariate Statistical Methods
}

\author{
Eugene K. Blythe ${ }^{1}$ and Donald J. Merhaut \\ Department of Botany and Plant Sciences, University of California, \\ Riverside, CA 92521-0124
}

Additional index words. principal components analysis, cluster analysis, Ward's method, air space, container capacity, bulk density, nursery production

\begin{abstract}
Nursery growers develop container substrate blends based on factors such as cost, availability of substrate components, and the physical and chemical properties of the blends. Comparative examination of potential substrate blends typically involves comparison of measured values one variable at a time; however, multivariate methods are available that can allow simultaneous consideration of all variables. In this study, 127 container substrate blends were prepared, each blend containing two to four of 11 individual substrate components with at least one inorganic component (soil, sand, soil + sand, soil + perlite) and at least one organic component (coir, peatmoss, compost, pine bark, cedar bark, redwood shavings, fine-grade coconut husk chips, and medium-grade coconut husk chips). One blend containing only soil and perlite was an exception. Mean values for air space, container capacity, and bulk density were determined using five samples of each blend in \#1 (2.84 L) containers. Among the 127 blends, air space ranged from $5.1 \%$ to $40.4 \%$ (by volume) and container capacity ranged from $24.8 \%$ to $59.4 \%$ (by volume). Bulk density among the blends ranged from $0.35 \mathrm{~g} \cdot \mathrm{cm}^{-3}$ to $1.00 \mathrm{~g} \cdot \mathrm{cm}^{-3}$ with bulk densities below and above $\approx 0.55 \mathrm{~g} \cdot \mathrm{cm}^{-3}$ represented almost exclusively by blends with and without perlite, respectively. Principal components analysis and hierarchical cluster analysis (Ward's method) were used to group the blends into eight groups based on the three physical property variables with each group distinguishable from all other groups based on simultaneous consideration of the three variables. In this study, we demonstrate that exploratory multivariate statistical techniques can be used to create groups of substrate blends, thus providing information to assist nursery growers in identifying and comparing substrate blends with similar or dissimilar physical properties among blends containing similar or different inorganic and organic components and proportions of those components.
\end{abstract}

The physical properties of containergrowing substrates, particularly air space, container capacity, and bulk density, have a significant impact on plant growth, and knowledge of these properties is essential in properly managing nursery irrigation and fertilization programs (Yeager et al., 2000). As such, physical properties of containergrowing substrates and individual substrate components have been investigated and reported in numerous research studies in past years (Bilderback et al., 1982; Bilderback and Lorscheider, 1995; Brown and Pokorny, 1975; Haynes and Goh, 1978) and continue to be emphasized in more recent studies (Abad et al., 2005; Bilderback et al., 2005; Blythe

Received for publication 22 Mar. 2006. Accepted for publication 6 June 2006 .

Mention of trade names does not imply product endorsement by the authors or the University of California.

We thank Monrovia Growers for supporting this study and its publication. We also thank Sai International Trading Corp. for donating materials used in this study.

${ }^{1}$ To whom reprint requests should be addressed; e-mail eugene.blythe@ucr.edu. et al., 2005; Cole et al., 2005; HernándezApaolaza et al., 2005).

Examination of container substrates based on physical property variables typically involves tabular reporting of measured values (Abad et al., 2005; Bilderback and Lorscheider, 1995; Bilderback et al., 2005; Chong, 2005; Haynes and Goh, 1978; Hernández-Apaolaza et al., 2005; Wiberg et al., 2005). When comparisons are made among these container substrates based on physical property variables, such comparisons are often made using a parametric, multiple comparison procedure (Abad et al., 2005; Bilderback et al., 2005; Goh and Haynes, 1977; Hernández-Apaolaza et al., 2005); in such cases, substrates are compared one physical property variable at a time.

Parametric models have been used to predict values of substrate physical properties. Burés et al. (1988) used parametric linear programming as a tool in selecting substrate blends based on physical and chemical characteristics of individual substrate components; however, their method involved certain restrictions and assumptions such as similar particle size distribution of the com- ponents used in their study, which may not be typical in actual nursery practice. Milks et al. (1989) used a five-parameter, nonlinear function to predict physical property values and found the model provided accurate predictions when compared with observed values for the five substrates used in their study.

Multivariate statistical methods, which allow for simultaneous consideration of multiple variables, can permit further examination and comparison of container substrates. Two such exploratory multivariate methods that require no distributional assumptions are principal components analysis (PCA) and cluster analysis (CLA). PCA, which reduces the dimensionality of multivariate data by creating new, uncorrelated variables from the original variables, has numerous and varied application in horticultural research. PCA has been used in examination of yield and quality components, taxonomic studies, classification of cultivars, and analysis of associations between plant or soil attributes and environmental characteristics (Broschat, 1979; Doi and Sakurai, 2004; Iezzoni and Pritts, 1991; Rhodes et al., 1971; Suo et al., 2005). The new variables generated by PCA may be used as input variables for other multivariate techniques such as CLA. CLA combines observations into groups such that each group is homogeneous with respect to certain characteristics and different from other groups with respect to those same characteristics with various methods available for calculating distances between clusters (Sharma, 1996). CLA can be used in a variety of studies such as grouping of species or cultivars based on morphologic, physiological, phytochemical, or genetic variables (Drogoudi et al., 2005; Gardner and Hokanson, 2005; Lee et al., 2004; Rhodes et al., 1971; Shearman, 1986). Kumar and Sharma (1993) used CLA to group soils based on morphologic, physical, and chemical characteristics, whereas Bredenkamp et al. (1983) used both PCA and CLA to identify habitat classes based on environmental (soil) variables.

The objectives of the present study were to: 1) provide measures of basic physical properties (air space, container capacity, and bulk density) for a broad range of container substrate blends containing at least one inorganic component and at least one organic component; 2) examine the use of exploratory multivariate techniques (PCA and CLA) for use in grouping substrate blends for comparative purposes; and 3 ) examine the composition of the groups of substrates generated through the use of such exploratory multivariate techniques.

\section{Materials and Methods}

Preparation of substrate blends. One hundred twenty-seven container substrate blends were prepared by mixing components in $15-\mathrm{L}$ batches in a portable cement mixer. Each substrate blend contained two to four of 11 individual substrate components (Table 1). Substrate blends contained at least one inorganic component and at least one organic 
Table 1. Substrate components used in the preparation of 127 container substrate blends.

\begin{tabular}{ll}
\hline Substrate component & \multicolumn{1}{c}{ Specifications } \\
$\begin{array}{l}\text { Inorganic } \\
\text { Soil }\end{array}$ & Coarse sandy loam $\approx 70 \%$ sand, 16\% silt, 14\% clay, <1\% organic matter) \\
$\begin{array}{l}\text { Sand } \\
\text { Perlite }\end{array}$ & Washed builders' sand \\
Organic & SaiCoir Growing Medium-regular grade (coir pith particles and \\
Coir & short fibers) \\
& BP-P (professional) grade \\
Peatmoss & Composted woody nursery plant trimmings; $20 \mathrm{~mm}$ screened \\
Compost & 19 mm screened \\
Pine bark & 19 mm screened \\
Cedar bark & $100 \%<9.51$ mm; $97 \%<6.35$ mm; $92 \%<4.75 \mathrm{~mm} ; 64 \%<2.38$ mm; \\
Redwood shavings & $29 \%<1.00$ mm; $14 \%<0.50$ mm \\
& Sai coconut husk chips- fine grade $(3.2-6.4 \mathrm{~mm}$ cube size) \\
Coconut chips (fine) & Sai coconut husk chips-medium grade $(19-25 \mathrm{~mm}$ cube size) \\
Coconut chips (medium)
\end{tabular}

component (with the exception of blend 1 , which contained soil and perlite but no organic components). Individual components in each substrate blend (expressed as percent by volume before blending) are shown in Table 2.

Determination of physical properties. Five \#1 injection-molded polypropylene containers $(2.84 \mathrm{~L}, 17.8 \mathrm{~cm}$ in height, $15.2 \mathrm{~cm}$ i.d.; Nursery Supplies, Orange, Calif.] were filled with each of the substrate blends. Containers were tamped 12 times during the filling process to facilitate settling of the substrate with additional substrate added as necessary to keep the surface of the substrate level with the top of the container. Filled containers of substrate were placed in larger buckets to which water was added until the substrate was thoroughly saturated such that the water level in the bucket was at the same height as the surface of the substrate. After $4 \mathrm{~h}$ in the larger buckets, the saturated containers of substrate were quickly removed from the buckets of water, placed immediately into individual aluminum collection pans, and weighed to determine the weight of the substrate and water in each container. The containers were then removed from the collection pans, covered with aluminum foil, allowed to drain freely for $24 \mathrm{~h}$, and weighed again to determine the weight of the substrate at container capacity. Containers of substrate were then allowed to air dry for 1 week after which time the substrate was transferred into wax-coated paper bags, placed in a $70{ }^{\circ} \mathrm{C}$ oven to dry thoroughly for $3 \mathrm{~d}$ to achieve constant weight, and weighed. Net weights obtained were used to calculate percent air space, container capacity, and bulk density.

Statistical analysis. Means of the three substrate physical property variables for each of the 127 blends were calculated using the MEANS procedure of SAS Version 9.1 (SAS Institute, Cary, N.C.) and were used for subsequent analyses. Goodness-of-fit tests [Kolmogorov-Smirnov Test (D), Cramervon Mises Test $\left(\mathrm{W}^{2}\right)$, Anderson-Darling Test $\left(\mathrm{A}^{2}\right)$ ] for the normal and lognormal distributions were run for each of the three variables using the UNIVARIATE procedure of SAS. Eigenvalues, eigenvectors, and principal components (PCs) were calculated using the correlation matrix with the PRINCOMP pro- cedure of SAS. Correlations between the three original variables and the PCs were calculated using the CORR procedure of SAS. Hierarchical cluster analyses were conducted for both the means of the three original variables and for the first two PCs with the CLUSTER and TREE procedures of SAS using the single linkage method, complete linkage method, average linkage method, centroid method, Gower's median method, and Ward's method. Four common heuristic statistics (Sharma, 1996), each of which provide information about the cluster solution at any given step, were used to evaluate cluster solutions and number of clusters present for each of the clustering methods: 1) $\mathrm{R}^{2}$, 2) semipartial $\mathrm{R}^{2}\left(\mathrm{SPR}^{2}\right), 3$ ) root-mean-square standard deviation (RMSSTD), and 4) distance between clusters (DBC) or, in the case of Ward's method, between-cluster sum of squares (BCSS). Descriptive statistics for each of the eight groups obtained from the eight-cluster solution provided by use of the first two PCs and Ward's method of clustering were calculated using the MEANS and UNIVARIATE procedures of SAS. Each of the eight groups was given a comparative rating [1 (lower) to 5 (higher)] for each of the three variables with the rating determined by a majority of the blends within that group falling within the first (lowest) to fifth (highest), respectively, of the five 20percentile ranges ( 0 th to $<20$ th, 20 th to $<40$ th, 40 th to $<60$ th, 60 th to $<80$ th, 80 th to 100 th) calculated for all 127 blends. Percentiles were obtained using the UNIVARIATE procedure of SAS.

\section{Results and Discussion}

Univariate and multivariate distribution of the physical property variables. The multivariate statistical methods used in this study require no assumption of multivariate normality. However, for future reference, the distributions of the three original variables were examined to indicate whether the 127 substrate blends could be considered as a representative sample from a population with multivariate normally distributed values of these variables.

Air space values exhibited a unimodal distribution (Fig. 1A) and showed no signif-
Monrovia Growers, Azusa, Calif.

Century Sand and Gravel, City of Industry, Calif. Paramount Perlite Co., Paramount, Calif.

Sai International Trading Corp., Oxnard, Calif.

Berger Peat Moss, Saint-Modeste, Canada

Monrovia Growers, Azusa, Calif.

RSA Soil Products, Orange, Calif.

Sierra Forest Products, Terra Bella, Calif.

RSA Soil Products, Orange, Calif.

Sai International Trading Corp., Oxnard, Calif. Sai International Trading Corp., Oxnard, Calif. icant deviation from a normal distribution (D: $\left.P=0.137, \mathrm{~W}^{2}: P=0.167, \mathrm{~A}^{2}: P=0.135\right)$. Container capacity values also exhibited a unimodal distribution (Fig. 1B) and showed no significant deviation from a normal distribution (D: $P>0.150, \mathrm{~W}^{2}: P=0.199, \mathrm{~A}^{2}: P=$ $0.108)$. Neither arcsine-square-root nor logit transformations were of value in approximating normality with either of these two variables. These results suggest that the values for air space and container capacity among the 127 blends could be representative of normally distributed values from a larger population of substrate blends.

Bulk density exhibited a bimodal distribution (Fig. 1C). With one exception, blends containing perlite were associated with bulk density values below $\approx 0.55 \mathrm{~g} \cdot \mathrm{cm}^{-3}$ and blends containing no perlite were associated with bulk density values above $\approx 0.55 \mathrm{~g} \cdot \mathrm{cm}^{-3}$. The distribution of bulk density values for the 43 blends containing perlite deviated significantly from a normal distribution (D: $P=$ $\left.0.025, \mathrm{~W}^{2}: P=0.022, \mathrm{~A}^{2}: P=0.017\right)$, but not from a log-normal distribution (D: $P=0.123$, $\left.\mathrm{W}^{2}: P=0.190, \mathrm{~A}^{2}: P=0.190\right)$. Similarly, the distribution of bulk density values for the 84 blends containing no perlite deviated significantly from a normal distribution (D: $P=$ $\left.0.042, \mathrm{~W}^{2}: P=0.022, \mathrm{~A}^{2}: P=0.013\right)$, but not from a log-normal distribution (D: $P>0.150$, $\left.\mathrm{W}^{2}: P=0.203, \mathrm{~A}^{2}: P=0.165\right)$. Likewise, air space values did not differ significantly from a normal distribution for the blends containing perlite (D: $P=0.130, \mathrm{~W}^{2}: P>0.250, \mathrm{~A}^{2}$ : $P>0.250)$ or the blends containing no perlite (D: $P>0.150, \mathrm{~W}^{2}: P>0.250, \mathrm{~A}^{2}: P=0.246$ ); neither did container capacity values differ significantly from a normal distribution for the blends containing perlite (D: $P>0.150$, $\left.\mathrm{W}^{2}: P=0.246, \mathrm{~A}^{2}: P=0.163\right)$ or the blends containing no perlite (D: $P>0.150, \mathrm{~W}^{2}: P>$ $\left.0.250, \mathrm{~A}^{2}: P>0.250\right)$. This suggests that values for air space, container capacity, and $\log$ (bulk density) among the blends containing perlite could be representative of multivariate normally distributed values from a larger population of blends containing perlite and likewise for a population of blends containing no perlite.

Although assumption of a multivariate normal distribution was not necessary for the multivariate statistical methods subsequently 
Table 2. Components, air space, container capacity, and bulk density of 127 container-growing substrate blends in order by substrate blend number.

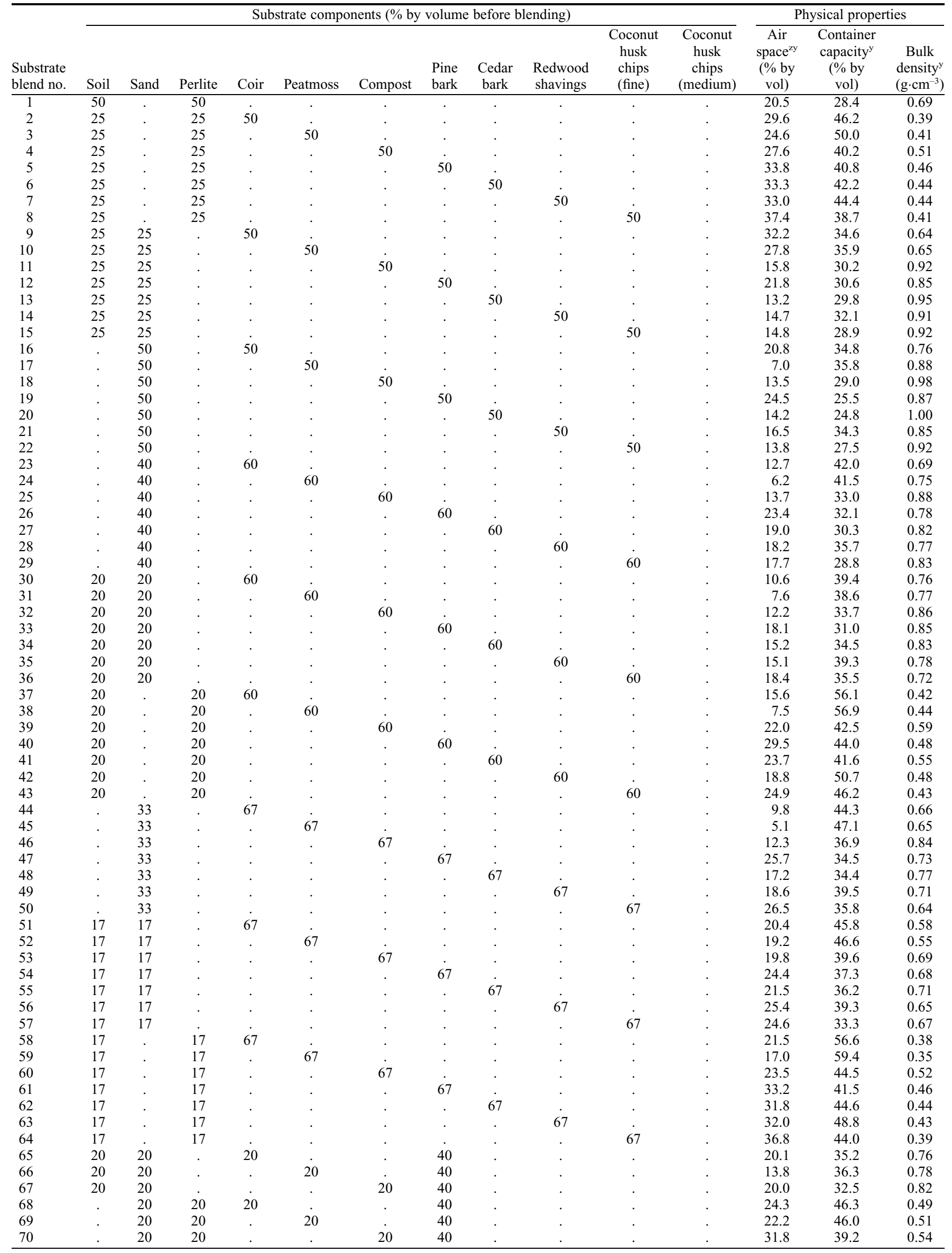

(Continued on next page) 
Table 2. (continued) Components, air space, container capacity, and bulk density of 127 container-growing substrate blends in order by substrate blend number.

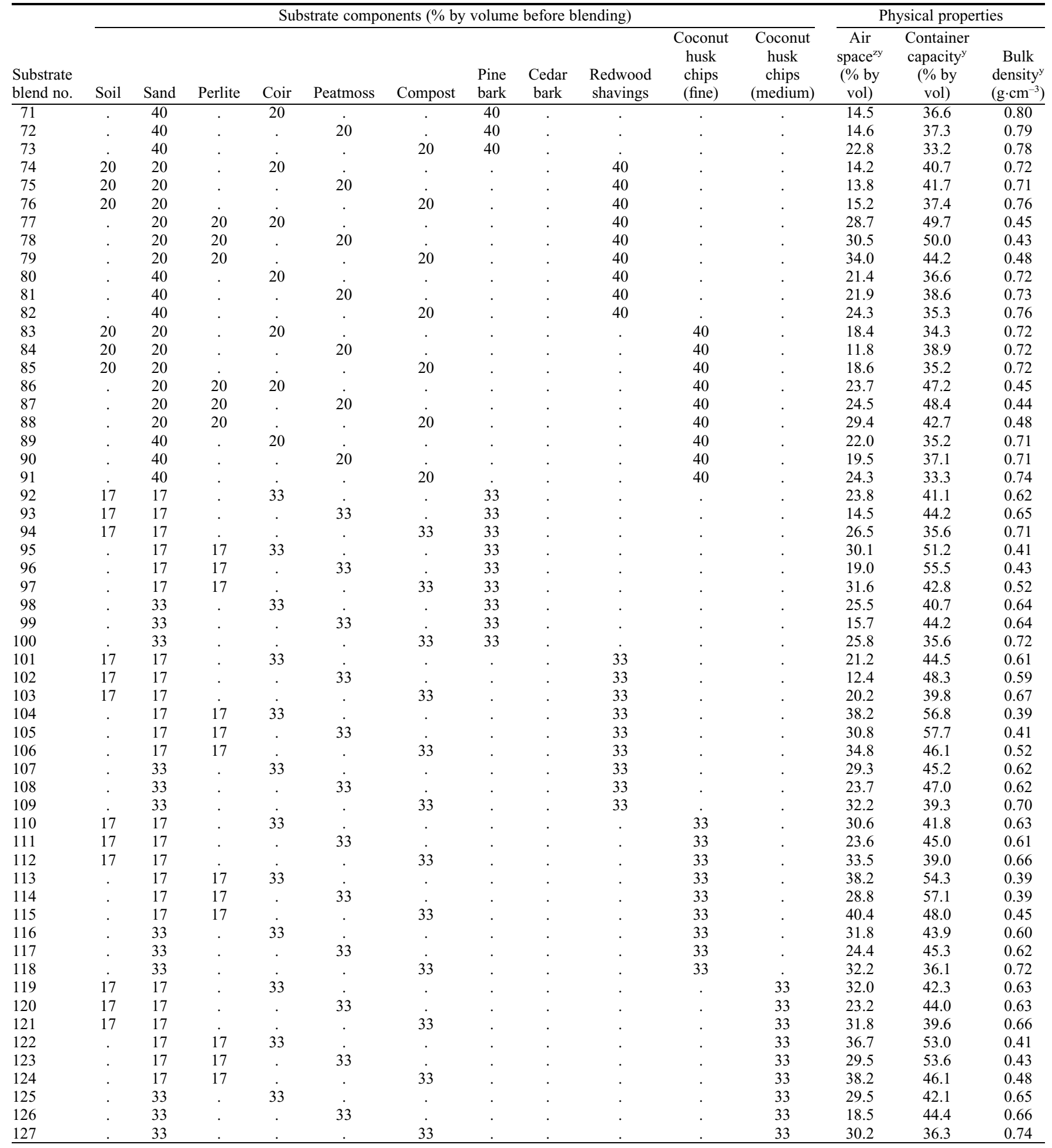

${ }^{\mathrm{z}}$ Air space at container capacity.

${ }^{\mathrm{y}}$ Mean of five replications.

used in this study, such information could be valuable when using other multivariate methods (such as multivariate analysis of variance) in which inferences about a population are to be made based on a random sample. Both the original and natural-logarithmtransformed values for bulk density were examined in the methods used in the remainder of this study with no appreciable difference in the results. Therefore, for sim- plicity, only results based on the original bulk density values are presented.

Principal components analysis. Air space and bulk density variables exhibited a moderately negative correlation, whereas container capacity and bulk density variables exhibited a strongly negative correlation (Table 3). Both the three original variables and new, uncorrelated variables (PCs) were used as input variables in subsequent cluster analyses. Eigenvalues and eigenvectors were calculated using the correlation matrix and the standardized values of the three variables (Table 4). The eigenvectors were then used to calculate PCs scores (the new variables) whose values were calculated as linear combinations of the original three variables using coefficients provided by the eigenvectors. The first eigenvalue alone accounted for almost $74 \%$ of the total variance and the 


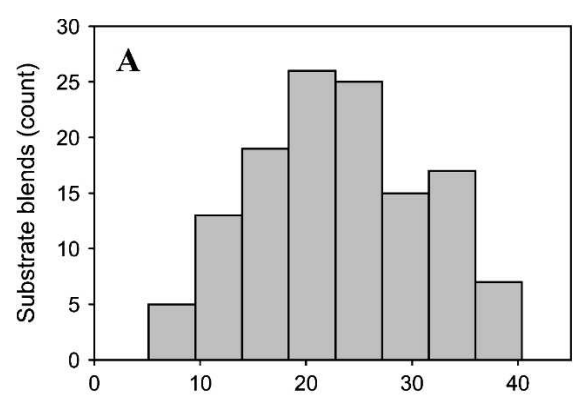

Air space ( $\%$ by volume at container capaciaty)
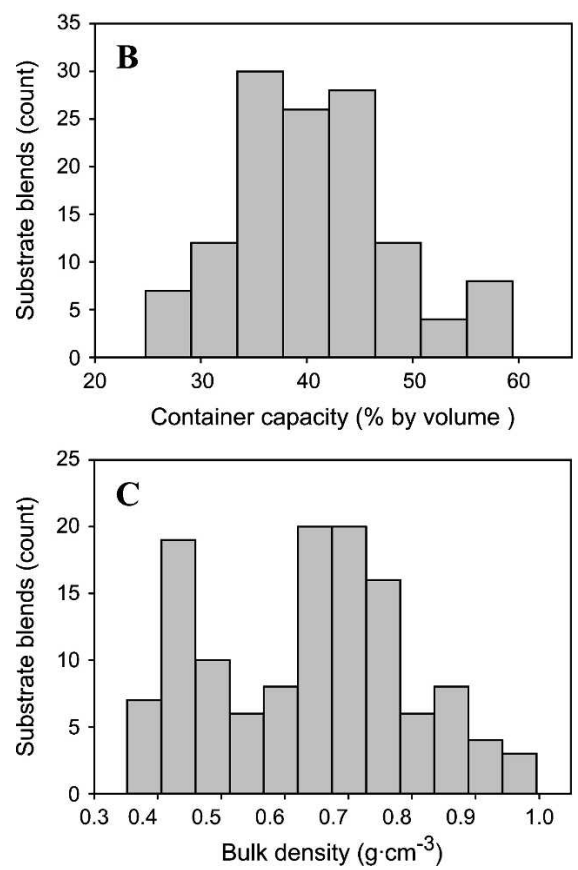

Fig. 1. Histograms showing the distribution of 127 container substrate blends for each of three physical property variables [(A) air space, $(\mathbf{B})$ container capacity, and (C) bulk density]. first two eigenvalues together accounted for almost $98 \%$ of the total variance. Therefore, only the first two PCs were used for subsequent analyses with little information being lost by elimination of the third PC.

The first PC could be interpreted as a "pore space component" and represents a contrast between the contents of the pore space (air space and container capacity) and the solid space (bulk density) with the contrast weighted more on the contents of the pore space. The second PC could be interpreted as a "dryness component" and repre- sents a contrast between the air space and the container capacity with the contrast weighted more on the air space. These apparent contrasts, as well as the relative importance of the original variables on the first two PCs, were also reflected in the correlations between the original variables and the first two PCs (Table 3).

Cluster analysis. Using the original variables, the six clustering methods (which each use different methods to determine how distances between clusters are calculated) either did not provide a distinct indication

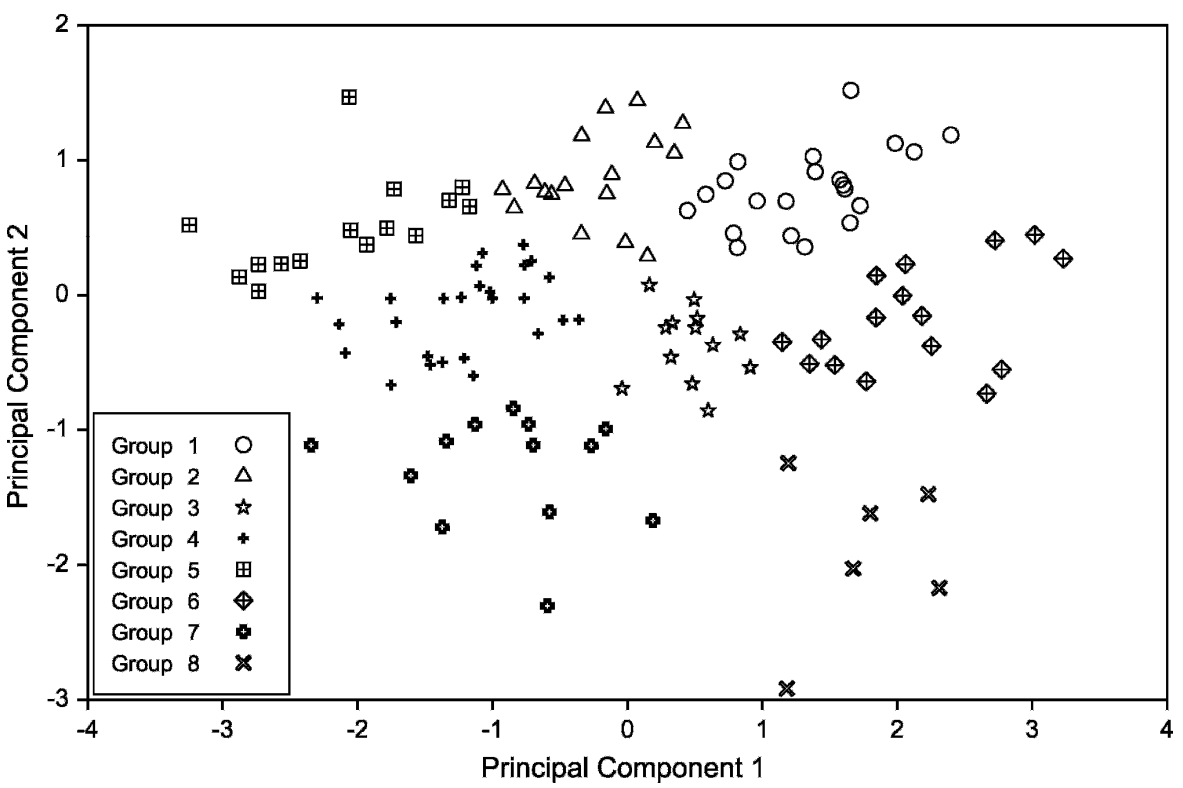

Fig. 2. Scatterplot of the first two principal components calculated from three physical property variables (air space, container capacity, and bulk density) for 127 container substrate blends, each point labeled according to group number as determined by the eight-cluster solution provided by Ward's method of hierarchical cluster analysis.

Table 3. Pearson correlation coefficients [and the associated $P$ values under the null hypothesis of zero correlation (in parentheses)] for three original variables [air $\operatorname{space}^{\mathrm{z}}\left(\%\right.$ by volume), container capacity (\% by volume), and bulk density $\left.\left(\mathrm{g} \cdot \mathrm{cm}^{-3}\right)\right]$ determined for 127 container substrate blends and for the original variables and three new variables (principal components) obtained using the correlation matrix of the standardized values of the three original variables.

\begin{tabular}{|c|c|c|c|c|c|c|}
\hline \multirow[b]{2}{*}{ Original variables } & \multicolumn{3}{|c|}{ Original variables } & \multicolumn{3}{|c|}{ Principal components (PCs) } \\
\hline & Air space & Container capacity & Bulk density & PC1 & $\mathrm{PC} 2$ & $\mathrm{PC} 3$ \\
\hline Air space & 1.0000 & 0.3024 & -0.6019 & 0.7036 & 0.7065 & 0.0762 \\
\hline & - & $(0.0005)$ & $(<0.0001)$ & $(<0.0001)$ & $(<0.0001)$ & $(0.3944)$ \\
\hline Bulk density & - & - & $\begin{array}{l}1.0000 \\
-\end{array}$ & $\begin{array}{c}-0.9753 \\
(<0.0001)\end{array}$ & $\begin{array}{c}0.0980 \\
(0.2727)\end{array}$ & $\begin{array}{c}0.1978 \\
(0.0258)\end{array}$ \\
\hline
\end{tabular}

${ }^{\mathrm{z}}$ Air space at container capacity.

Table 4. Eigenvalues obtained from the correlation matrix of the standardized values of three variables ${ }^{\mathrm{z}}$ [air space ${ }^{\mathrm{y}}(\%$ by volume), container capacity ( $\%$ by volume), and bulk density $\left(\mathrm{g} \cdot \mathrm{cm}^{-3}\right)$ ] determined for 127 container substrate blends; proportions and cumulative proportions of the total variance explained by the eigenvalues; and formulas for the calculation of principal components using the corresponding eigenvectors.

\begin{tabular}{lcccc}
\hline & \multicolumn{2}{c}{ Eigenvalues of the correlation matrix } & & Calculation of principal components (PCs) using eigenvectors \\
\hline Sequence & Eigenvalue & Proportion & Cumulative proportion & \\
\hline 1 & 2.2098 & 0.7366 & 0.7366 & $\begin{array}{c}\text { PC1 }=(0.473328 \times \text { air space })+(0.587792 \times \text { container capacity })- \\
(0.656095 \times \text { bulk density })\end{array}$ \\
2 & 0.7198 & 0.2399 & 0.9765 & $\begin{array}{c}\text { PC } 2=(0.832699 \times \text { air space })-(0.541528 \times \text { container capacity })+ \\
(0.115585 \times \text { bulk density })\end{array}$ \\
3 & 0.0704 & 0.0235 & 1.0000 & $\begin{array}{c}\text { PC } 3=(0.287354 \times \text { air space })+(0.601039 \times \text { container capacity })+ \\
(0.745775 \times \text { bulk density })\end{array}$ \\
\hline
\end{tabular}

${ }^{2}$ Mean of five replications for each blend.

${ }^{\mathrm{y}}$ Air space at container capacity. 
of the number of clusters or did not provide a consistent number of clusters from one evaluative statistic $\left(\mathrm{R}^{2}, \mathrm{SPR}^{2}, \mathrm{RMSSTD}\right.$, and $\mathrm{DBC}$ or BCSS) to another (results not presented). However, the complete linkage method and Ward's method appeared to suggest solutions with $\approx 10$ clusters and eight clusters, respectively.

Using the two new variables (first two PCs), Ward's method provided the clearest and most consistent results suggesting an eight-cluster solution (Fig. 2). The other methods provided less precise solutions when evaluated using the four statistics. Using Ward's method, the $\mathrm{R}^{2}$ statistic exhibited a rapid initial increase with an increasing potential number of clusters. The rate of increase was notably reduced beyond eight clusters (Fig. 3A). The $\mathrm{SPR}^{2}$ and BCSS
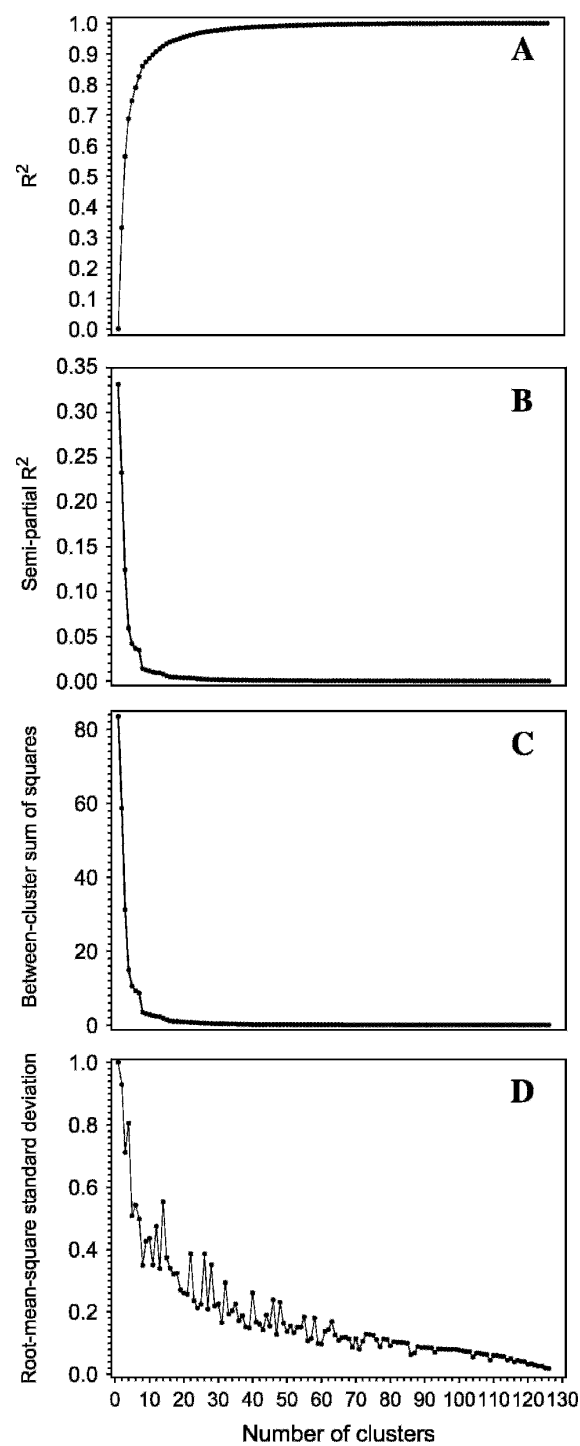

Fig. 3. Plots of four heuristic statistics [(A) R2, (B) semipartial R2, (C) between-cluster sum of squares, and (D) root-mean-square standard deviation] used to select an optimal number of clusters (groups) developed using principal components and Ward's method of hierarchical cluster analysis based on physical property variables (air space, container capacity, and bulk density) determined for 127 container substrate blends. statistics exhibited rapid initial decreases with an increasing potential number of clusters and then changed little beyond eight clusters (Fig. 3B, C). Likewise, RMSSTD exhibited a rapid decrease with an increasing potential number of clusters (from one to eight) and then a slower overall decrease beyond eight clusters (Fig. 3D). From a practical standpoint, eight appears to be a workable number of clusters. The eight-cluster solution is shown in Figure 4 with the BCSS indicated at each step of cluster formation.

Ward's method, rather than calculating distances between clusters (as is the case with the other clustering methods used in this study), forms clusters by maximizing homogeneity within the clusters by minimizing the within-cluster sums of squares (Sharma, 1996; Ward, 1963). Several comparative studies have shown Ward's method to outperform other hierarchical clustering methods (Blashfield, 1976; Kuiper and Fisher, 1975; Mojena, 1977).

The eight-cluster solution developed using Ward's method and the two new variables provided eight groups of substrate blends with similar physical properties based on the values of the three original variables (Table 5). From a multivariate perspective, none of the eight groups exhibited any overlap in the three-dimensional separations between the clusters as can be noted in the four perspectives of Figure 5A-D. From a univariate perspective, when minimum-maximum ranges for each group and variable (Table 6) were examined in a pairwise fashion one variable at a time, there was no overlap in at least one-half of the 24 pairwise cases for

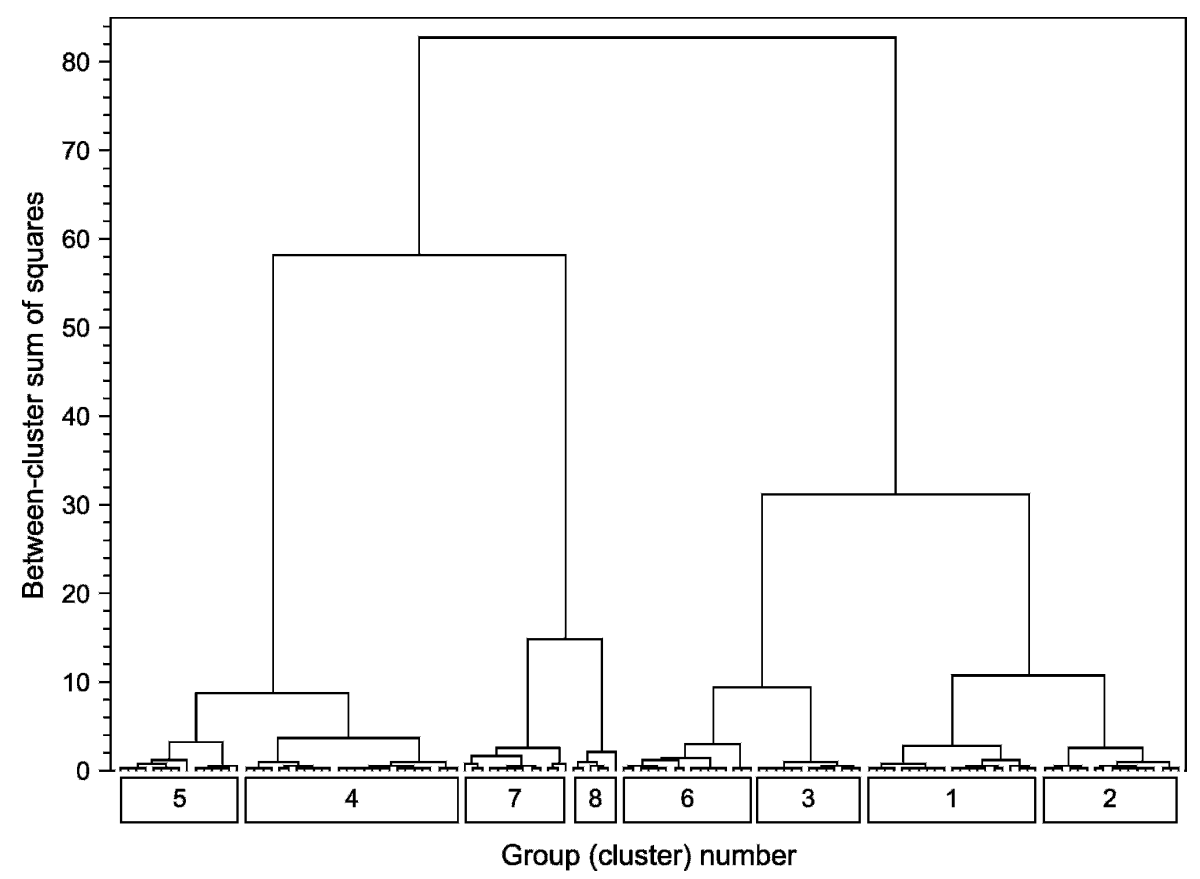

Fig. 4. Dendrogram showing formation of eight groups [each group designated by an identification number (1-18)] as obtained from the eight-cluster solution selected using principal components and Ward's method of hierarchical cluster analysis based on physical property variables (air space, container capacity, and bulk density) determined for 127 container substrate blends with the betweencluster sum of squares statistic at each step of cluster formation. 
Table 5. Components, air space, container capacity, and bulk density of 127 container-growing substrate blends in order by group number and then by substrate blend number. ${ }^{z}$

\begin{tabular}{|c|c|c|c|c|c|c|c|c|c|c|c|c|c|c|}
\hline \multirow[b]{2}{*}{$\begin{array}{l}\text { Substrate } \\
\text { blend no. }\end{array}$} & \multicolumn{11}{|c|}{ Substrate components ( $\%$ by volume before blending) } & \multicolumn{3}{|c|}{ Physical properties } \\
\hline & Soil & Sand & Perlite & Coir & Peatmoss & Compost & $\begin{array}{l}\text { Pine } \\
\text { bark }\end{array}$ & $\begin{array}{l}\text { Cedar } \\
\text { bark }\end{array}$ & $\begin{array}{l}\text { Redwood } \\
\text { shavings }\end{array}$ & $\begin{array}{l}\text { Coconut } \\
\text { husk } \\
\text { chips } \\
\text { (fine) }\end{array}$ & $\begin{array}{c}\text { Coconut } \\
\text { husk } \\
\text { chips } \\
\text { (medium) }\end{array}$ & $\begin{array}{c}\text { Air } \\
\text { space }^{y x} \\
(\% \text { by } \\
\text { vol }) \\
\end{array}$ & $\begin{array}{c}\text { Container } \\
\text { capacity }^{\mathrm{x}} \\
(\% \text { by } \\
\text { vol })\end{array}$ & $\begin{array}{c}\text { Bulk } \\
\text { density } \\
\left(\mathrm{g} \cdot \mathrm{cm}^{-3}\right)\end{array}$ \\
\hline \multicolumn{15}{|c|}{ Group 1} \\
\hline 4 & 25 & . & 25 & . & . & 50 & & . & . & . & . & 27.6 & 40.2 & 0.51 \\
\hline 5 & 25 & . & 25 & . & . & . & 50 & . & . & . & . & 33.8 & 40.8 & 0.46 \\
\hline 6 & 25 & . & 25 & . & . & . & & 50 & . & . & . & 33.3 & 42.2 & 0.44 \\
\hline 40 & 20 & . & 20 & . & . & . & 60 & . & . & . & . & 29.5 & 44.0 & 0.48 \\
\hline 61 & 17 & . & 17 & . & . & . & 67 & 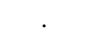 & . & . & . & 33.2 & 41.5 & 0.46 \\
\hline 62 & 17 & . & 17 & . & . & . & 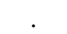 & 67 & . & . & . & 31.8 & 44.6 & 0.44 \\
\hline 64 & 17 & & 17 & . & . & . & & . & . & 67 & . & 36.8 & 44.0 & 0.39 \\
\hline 70 & 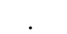 & 20 & 20 & . & . & 20 & 40 & . & . & . & . & 31.8 & 39.2 & 0.54 \\
\hline 79 & 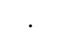 & 20 & 20 & . & . & 20 & & . & 40 & & . & 34.0 & 44.2 & 0.48 \\
\hline 88 & . & 20 & 20 & . & . & 20 & & . & . & 40 & . & 29.4 & 42.7 & 0.48 \\
\hline 115 & & 17 & 17 & & . & 33 & . & . & . & 33 & . & 40.4 & 48.0 & 0.45 \\
\hline 116 & & 33 & . & 33 & . & . & . & . & . & 33 & 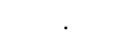 & 31.8 & 43.9 & 0.60 \\
\hline 119 & 17 & 17 & . & 33 & . & . & . & . & . & . & 33 & 32.0 & 42.3 & 0.63 \\
\hline 124 & . & 17 & 17 & & . & 33 & . & . & . & . & 33 & 38.2 & 46.1 & 0.48 \\
\hline 125 & . & 33 & . & 33 & . & . & 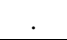 & . & . & . & 33 & 29.5 & 42.1 & 0.65 \\
\hline \multicolumn{15}{|c|}{ Group 2} \\
\hline 9 & 25 & 25 & . & 50 & & . & & . & . & . & . & 32.2 & 34.6 & 0.64 \\
\hline 10 & 25 & 25 & . & . & 50 & . & & . & . & . & . & 27.8 & 35.9 & 0.65 \\
\hline 47 & . & 33 & . & . & . & . & 67 & . & . & . & . & 25.7 & 34.5 & 0.73 \\
\hline 50 & & 33 & . & . & . & . & & . & . & 67 & . & 26.5 & 35.8 & 0.64 \\
\hline 54 & 17 & 17 & . & . & . & . & 67 & . & . & . & . & 24.4 & 37.3 & 0.68 \\
\hline 56 & 17 & 17 & . & . & . & . & . & . & 67 & & . & 25.4 & 39.3 & 0.65 \\
\hline 57 & 17 & 17 & . & . & . & . & 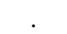 & . & . & 67 & . & 24.6 & 33.3 & 0.67 \\
\hline 82 & . & 40 & . & . & . & 20 & 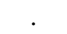 & . & 40 & . & . & 24.3 & 35.3 & 0.76 \\
\hline 91 & & 40 & . & . & . & 20 & & . & . & 40 & . & 24.3 & 33.3 & 0.74 \\
\hline 94 & 17 & 17 & . & . & . & 33 & 33 & . & . & . & . & 26.5 & 35.6 & 0.71 \\
\hline 98 & & 33 & . & 33 & . & . & 33 & . & . & . & . & 25.5 & 40.7 & 0.64 \\
\hline 100 & 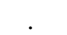 & 33 & . & 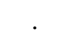 & . & 33 & 33 & . & . & . & . & 25.8 & 35.6 & 0.72 \\
\hline 109 & & 33 & . & . & . & 33 & . & . & 33 & & . & 32.2 & 39.3 & 0.70 \\
\hline 112 & 17 & 17 & . & . & . & 33 & . & . & . & 33 & . & 33.5 & 39.0 & 0.66 \\
\hline 118 & & 33 & . & . & . & 33 & 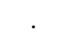 & . & . & 33 & . & 32.2 & 36.1 & 0.72 \\
\hline 121 & 17 & 17 & . & . & . & 33 & 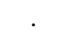 & . & . & . & 33 & 31.8 & 39.6 & 0.66 \\
\hline 127 & & 33 & . & . & . & 33 & 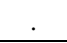 & . & . & . & 33 & 30.2 & 36.3 & 0.74 \\
\hline \multicolumn{15}{|c|}{ Group 3} \\
\hline 39 & 20 &. & 20 &. &. & 60 & r. & 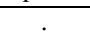 & . & . & . & 22.0 & 42.5 & 0.59 \\
\hline 41 & 20 & & 20 & . & . & . & 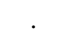 & 60 & . & . & . & 23.7 & 41.6 & 0.55 \\
\hline 51 & 17 & 17 & . & 67 & & . & . & . & . & . & . & 20.4 & 45.8 & 0.58 \\
\hline 52 & 17 & 17 & & 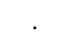 & 67 & 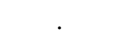 & . & . & . & . & . & 19.2 & 46.6 & 0.55 \\
\hline 60 & 17 & 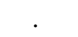 & 17 & . & . & 67 & & . & . & . & . & 23.5 & 44.5 & 0.52 \\
\hline 69 & & 20 & 20 & . & 20 &. & 40 & . & . & . & . & 22.2 & 46.0 & 0.51 \\
\hline 92 & 17 & 17 & 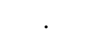 & 33 & . & . & 33 & . & . & . & . & 23.8 & 41.1 & 0.62 \\
\hline 101 & 17 & 17 & . & 33 & & . & . & . & 33 & . & . & 21.2 & 44.5 & 0.61 \\
\hline 108 & & 33 & . & . & 33 & . & . & . & 33 & & . & 23.7 & 47.0 & 0.62 \\
\hline 111 & 17 & 17 & . & . & 33 & . & . & . & . & 33 & . & 23.6 & 45.0 & 0.61 \\
\hline 117 & & 33 & . & . & 33 & . & . & . & . & 33 & & 24.4 & 45.3 & 0.62 \\
\hline 120 & 17 & 17 & . & . & 33 & . & . & . & . & . & 33 & 23.2 & 44.0 & 0.63 \\
\hline 126 & 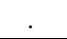 & 33 & . & . & 33 & . & . & . & . & . & 33 & 18.5 & 44.4 & 0.66 \\
\hline \multicolumn{15}{|c|}{ Group 4} \\
\hline 14 & 25 & 25 & . & . & . & . & . & . & 50 & . & . & 14.7 & 32.1 & 0.91 \\
\hline 16 & . & 50 & . & 50 & . & . & . & . & . & . & . & 20.8 & 34.8 & 0.76 \\
\hline 21 & 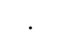 & 50 & . & . & . & . & . & . & 50 & . & . & 16.5 & 34.3 & 0.85 \\
\hline 25 & . & 40 & . & . & . & 60 & . & . & . & . & . & 13.7 & 33.0 & 0.88 \\
\hline 28 & & 40 & . & . & . & . & . & . & 60 & . & . & 18.2 & 35.7 & 0.77 \\
\hline 32 & 20 & 20 & . & . & . & 60 & 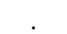 & 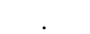 & . & . & . & 12.2 & 33.7 & 0.86 \\
\hline 34 & 20 & 20 & . & . & . & . & . & 60 & . & . & . & 15.2 & 34.5 & 0.83 \\
\hline 35 & 20 & 20 & . & . & . & . & . & . & 60 & . & . & 15.1 & 39.3 & 0.78 \\
\hline 36 & 20 & 20 & . & . & . & . & . & . & . & 60 & . & 18.4 & 35.5 & 0.72 \\
\hline 46 & & 33 & . & . & . & 67 & . & . & . & . & . & 12.3 & 36.9 & 0.84 \\
\hline 48 & . & 33 & . & . & . & . & . & 67 & . & . & . & 17.2 & 34.4 & 0.77 \\
\hline 49 & & 33 & . & . & . & . & . & . & 67 & . & . & 18.6 & 39.5 & 0.71 \\
\hline 53 & 17 & 17 & . & . & . & 67 & & . & . & . & . & 19.8 & 39.6 & 0.69 \\
\hline
\end{tabular}

(Continued on next page) 
Table 5. (continued) Components, air space, container capacity, and bulk density of 127 container-growing substrate blends in order by group number and then by substrate blend number.

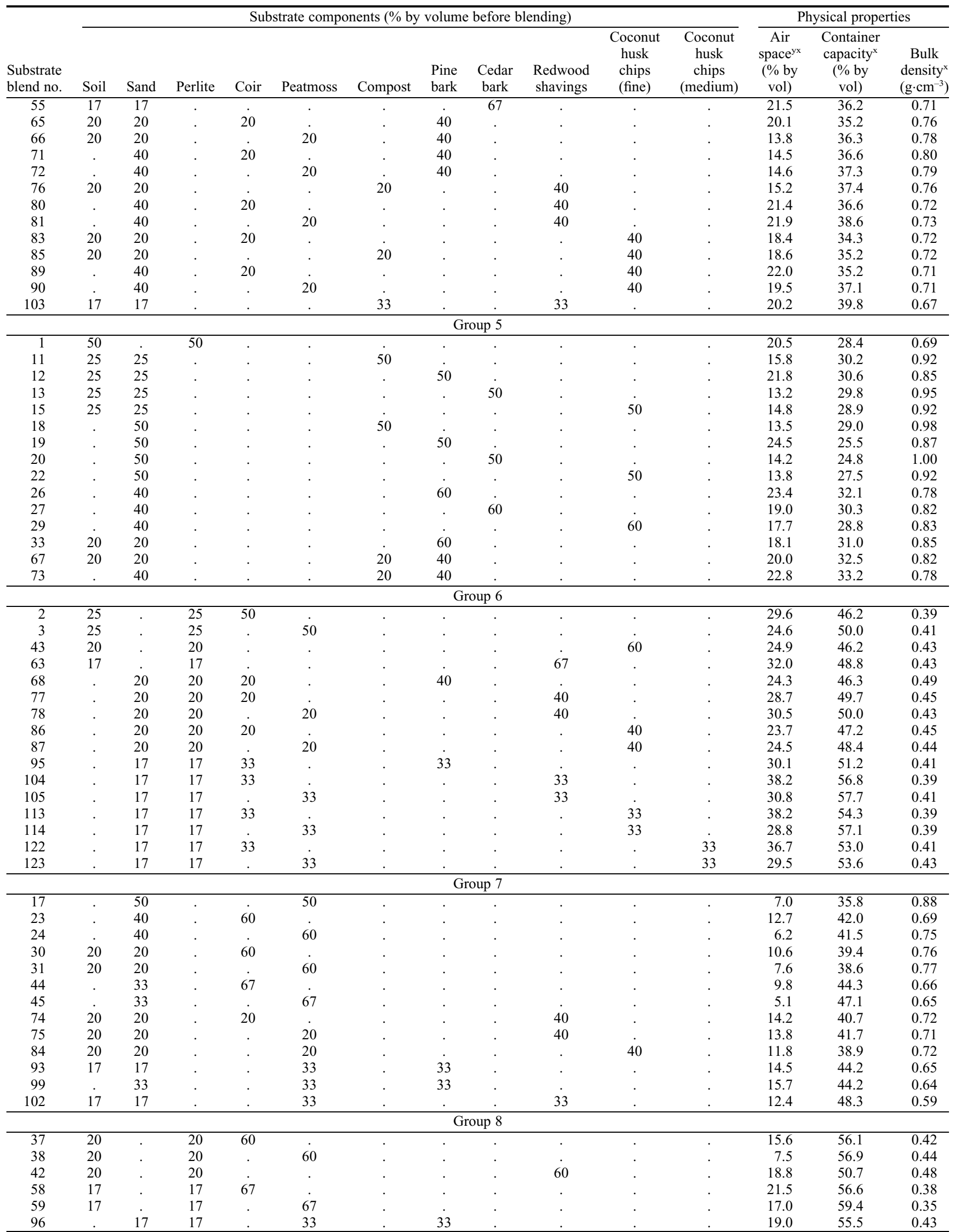

${ }^{\mathrm{z}}$ The eight groups were created using principal components and hierarchical cluster analysis (Ward's method).

yAir space at container capacity.

${ }^{\mathrm{x}}$ Mean of five replications. 

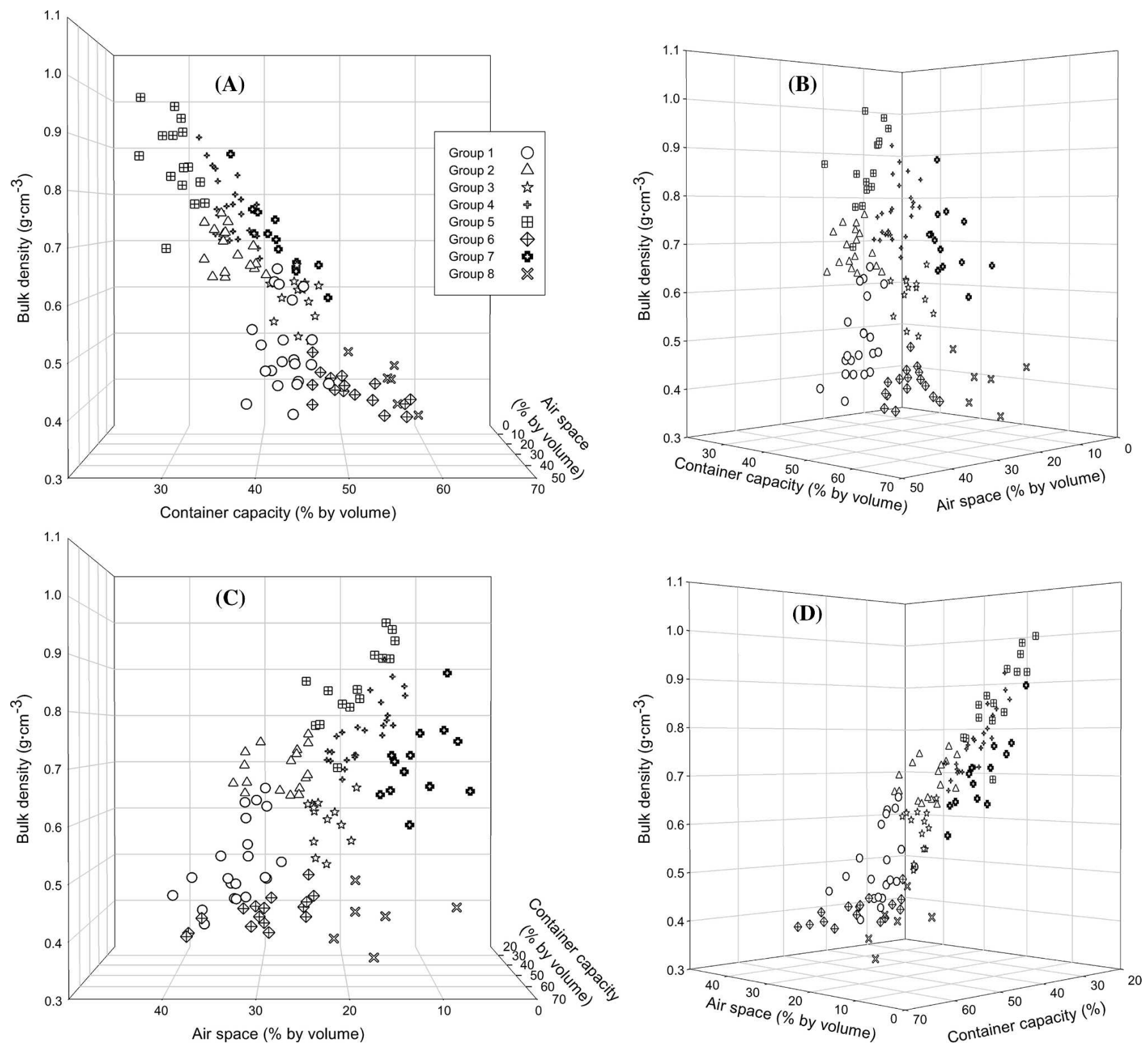

Fig. 5. Scatterplots of air space, container capacity, and bulk density for 127 container substrate blends shown from four different perspectives [(A) through (D) showing a progressive $45^{\circ}$ rotation about the vertical axis], each point labeled according to group number as obtained from the eight-cluster solution selected using principal components and Ward's method of hierarchical cluster analysis.

However, results from the nonhierarchical method provided no improvement in the ability to distinguish clusters from either a multivariate perspective (based on graphic examination) or univariate perspective (based on overlap of ranges).

Group characteristics. Characteristics of the eight groups of substrate blends are summarized in Table 7 . The trio of ratings [1 (lower) to 5 (higher)] for air space, container capacity, and bulk density was unique for each of the eight groups of substrate blends. No group with blends containing perlite had a bulk density rating greater than 2 , which was consistent with the earlier observation of a bimodal distribution for the bulk density variable alone. Otherwise, no single component served as the sole influence on any of the three physical property ratings among the eight groups; rather, they jointly influenced the ratings.

In general, air space and container capacity ratings appeared to be most influenced by the content of inorganic components, coir, and peatmoss, whereas bulk density ratings appeared to be most influenced by the inorganic components. The influence of compost and the coarser organic components was more variable. Group 7, with the lowest air space rating and an intermediate to higher bulk density rating, contained at least $33 \%$ sand or soil + sand, never contained perlite, always contained coir or peatmoss, never contained compost, and contained either none or one of three of the coarser organic components. In contrast, group 1, with the highest air space rating, contained no more than $33 \%$ soil or sand, often contained perlite, sometimes contained coir, sometimes contained compost, and almost always contained one of the five coarser organic components.

Groups 6 and 8, with the highest container capacity ratings and lowest bulk density ratings among all groups, contained blends that tended to be lower in soil or sand content, always contained perlite, most often contained coir or peatmoss, and never contained compost. In contrast, group 5 (excluding blend 1, which contained only soil and perlite), with the lowest container capacity rating and highest bulk density rating, contained blends that tended to be higher in soil or sand content, never contained perlite, never contained coir or peatmoss, and sometimes contained compost.

Numerous substrate blends included in this study contained higher proportions of 
Table 6. Minimum, maximum, and mean air space at container capacity, water content at container capacity, and bulk density of eight groups of 127 containergrowing substrate blends created using principal components analysis and cluster analysis (with Ward's hierarchical clustering method).

\begin{tabular}{|c|c|c|c|c|c|c|c|c|c|c|}
\hline \multirow[b]{2}{*}{ Group } & \multirow[b]{2}{*}{$\mathrm{n}^{\mathrm{y}}$} & \multicolumn{3}{|c|}{ Air space $(\%$ by vol) } & \multicolumn{3}{|c|}{ Container capacity ${ }^{z}(\%$ by vol) } & \multicolumn{3}{|c|}{ Bulk density $\left(\mathrm{g} \cdot \mathrm{cm}^{-3}\right)$} \\
\hline & & Minimum & Maximum & Mean & Minimum & Maximum & Mean & Minimum & Maximum & Mean \\
\hline 1 & 21 & 27.6 & 40.4 & 32.9 & 38.7 & 48.0 & 43.1 & 0.39 & 0.65 & $\overline{0.51}$ \\
\hline 2 & 17 & 24.3 & 33.5 & 27.8 & 33.3 & 40.7 & 36.6 & 0.64 & 0.76 & 0.69 \\
\hline 3 & 13 & 18.5 & 24.4 & 22.3 & 41.1 & 47.0 & 44.5 & 0.51 & 0.66 & 0.59 \\
\hline 4 & 26 & 12.2 & 22.0 & 17.5 & 32.1 & 39.8 & 36.1 & 0.67 & 0.91 & 0.77 \\
\hline 5 & 15 & 13.2 & 24.5 & 18.2 & 24.8 & 33.2 & 29.5 & 0.69 & 1.00 & 0.87 \\
\hline 6 & 16 & 23.7 & 38.2 & 29.7 & 46.2 & 57.7 & 51.0 & 0.39 & 0.49 & 0.42 \\
\hline 7 & 13 & 5.1 & 15.7 & 10.9 & 35.8 & 48.3 & 42.1 & 0.59 & 0.88 & 0.71 \\
\hline 8 & 6 & 7.5 & 21.5 & 16.6 & 50.7 & 59.4 & 55.9 & 0.35 & 0.48 & 0.42 \\
\hline
\end{tabular}

${ }^{\mathrm{z}}$ Air space at container capacity.

${ }^{\mathrm{y}} \mathrm{n}=$ number of substrate blends per group.

Table 7. Comparative ratings of air space, container capacity, and bulk density for eight groups of substrate blends along with a summary of substrate components for each group. ${ }^{\mathrm{C}}$

\begin{tabular}{|c|c|c|c|c|c|c|c|c|c|}
\hline \multirow[b]{2}{*}{$\begin{array}{l}\text { Group } \\
\text { number }\end{array}$} & \multirow[b]{2}{*}{$\mathrm{n}^{\mathrm{y}}$} & \multicolumn{3}{|c|}{ Comparative rating $^{\mathrm{x}}$} & \multicolumn{5}{|c|}{ Substrate components } \\
\hline & & $\begin{array}{c}\text { Air } \\
\text { space }^{w}\end{array}$ & $\begin{array}{l}\text { Container } \\
\text { capacity }\end{array}$ & $\begin{array}{c}\text { Bulk } \\
\text { density }\end{array}$ & Soil or sand & Perlite & $\begin{array}{l}\text { Coir or } \\
\text { peat }\end{array}$ & Compost & Coarser organics $^{\mathrm{v}}$ \\
\hline$\overline{1}$ & 21 & 5 & 4 & 2 & $\begin{array}{l}(9)^{\mathrm{u}} 17 \% \text { to } 25 \% \text { soil } \\
\text { (10) } 17 \% \text { to } 33 \% \text { sand }\end{array}$ & $\begin{array}{l}\text { (5) } 0 \% \\
\text { (16) } 17 \% \text { to } 25 \%\end{array}$ & $\begin{array}{l}\text { (16) } 0 \% \\
\text { (5) } 33 \% \text { coir } \\
\text { only }^{\mathrm{t}}\end{array}$ & $\begin{array}{l}\text { (13) } 0 \% \\
\text { (7) } 20 \% \text { to } 33 \%\end{array}$ & $\begin{array}{l}\text { (20) PB, CB, RS, CF, CM } \\
\text { (1) none }\end{array}$ \\
\hline 2 & 17 & 4 & 2 & 3 & $\begin{array}{l}\text { (2) } 33 \% \text { soil }+ \text { sand } \\
\text { (9) } 33 \% \text { or } 40 \% \text { sand } \\
\text { (8 } 33 \% \text { or } 50 \% \text { soil }+ \text { sand }\end{array}$ & (17) $0 \%$ & $\begin{array}{l}\text { (14) } 0 \% \\
\text { (3) } 33 \% \text { or } 50 \%\end{array}$ & $\begin{array}{l}\text { (1) } 50 \% \\
\text { (8) } 0 \% \\
\text { (9) } 20 \% \text { or } 33 \%\end{array}$ & $\begin{array}{l}\text { (15) PB, RS, CF, CM } \\
\text { (2) none }\end{array}$ \\
\hline 3 & 13 & 3 & 4 & 2 & $\begin{array}{l}\text { (2) } 17 \% \text { or } 20 \% \text { soil } \\
\text { (4) } 20 \% \text { or } 33 \% \text { sand } \\
\text { (7) } 33 \% \text { soil }+ \text { sand }\end{array}$ & $\begin{array}{l}\text { (9) } 0 \% \\
\text { (4) } 17 \% \text { or } 20 \%\end{array}$ & $\begin{array}{l}\text { (3) } 0 \% \\
\text { (10) } 33 \% \text { to } 67 \%\end{array}$ & $\begin{array}{l}\text { (11) } 0 \% \\
\text { (2) } 60 \% \text { or } 67 \%\end{array}$ & $\begin{array}{l}\text { (9) PB, CB, RS, CF, CM } \\
\text { (4) none }\end{array}$ \\
\hline 4 & 26 & 2 & 2 & 4 & $\begin{array}{l}\text { (13) } 33 \% \text { to } 50 \% \text { sand } \\
\text { (13) } 33 \% \text { to } 50 \% \text { soil }+ \text { sand }\end{array}$ & (26) $0 \%$ & $\begin{array}{l}\text { (16) } 0 \% \\
\text { (9) } 20 \% \\
\text { (1) } 50 \%\end{array}$ & $\begin{array}{l}\text { (19) } 0 \% \\
\text { (3) } 20 \% \text { or } 33 \% \\
\text { (4) } 60 \% \text { or } 67 \%\end{array}$ & $\begin{array}{l}\text { (21) } \mathrm{PB}, \mathrm{CB}, \mathrm{RS}, \mathrm{CF} \\
\text { (5) none }\end{array}$ \\
\hline 5 & 15 & 2 & 1 & 5 & $\begin{array}{l}\text { (1) } 50 \% \text { soil } \\
\text { (8) } 40 \% \text { or } 50 \% \text { sand } \\
\text { (6) } 40 \% \text { or } 50 \% \text { soil }+ \text { sand }\end{array}$ & $\begin{array}{l}\text { (14) } 0 \% \\
\text { (1) } 50 \% \mathrm{z}\end{array}$ & (15) $0 \%$ & $\begin{array}{l}\text { (11) } 0 \% \\
\text { (2) } 20 \% \\
\text { (2) } 50 \%\end{array}$ & $\begin{array}{l}\text { (12) } \mathrm{PB}, \mathrm{CB}, \mathrm{CF} \\
\text { (3) none }\end{array}$ \\
\hline 6 & 16 & 4 & 5 & 1 & $\begin{array}{l}\text { (4) } 17 \% \text { to } 25 \% \text { soil } \\
\text { (12) } 17 \% \text { or } 20 \% \text { sand }\end{array}$ & (16) $17 \%$ to $25 \%$ & $\begin{array}{l}\text { (2) } 0 \% \\
\text { (14) } 20 \% \text { to } 50 \%\end{array}$ & (16) $0 \%$ & $\begin{array}{l}\text { (14) PB, RS, CF, CM } \\
\text { (2) none }\end{array}$ \\
\hline 7 & 13 & 1 & 3 & 4 & $\begin{array}{l}\text { (6) } 33 \% \text { to } 50 \% \text { sand } \\
\text { (7) } 33 \% \text { or } 40 \% \text { soil }+ \text { sand }\end{array}$ & (13) $0 \%$ & (13) $20 \%$ to $67 \%$ & (13) $0 \%$ & $\begin{array}{l}\text { (6) PB, RS, CF } \\
\text { (7) none }\end{array}$ \\
\hline 8 & 6 & 2 & 5 & 1 & $\begin{array}{l}\text { (5) } 17 \% \text { or } 20 \% \text { soil } \\
\text { (1) } 17 \% \text { sand }\end{array}$ & (6) $17 \%$ to $20 \%$ & $\begin{array}{l}\text { (1) } 0 \% \\
\text { (5) } 33 \% \text { to } 67 \%\end{array}$ & (6) $0 \%$ & $\begin{array}{l}\text { (4) PB, RS } \\
\text { (2) none }\end{array}$ \\
\hline
\end{tabular}

${ }^{\mathrm{z}}$ Groups of substrate blends were created from 127 individual blends using principal components analysis and cluster analysis (with Ward's hierarchical clustering method). Each substrate blend contained two to four of 11 individual substrate components with at least one inorganic component and at least one organic component. Blend 1 with $50 \%$ soil $+50 \%$ perlite (and no organic components) was the single, exceptional case and is included in group 5 .

${ }^{\mathrm{y}} \mathrm{n}=$ total number of substrate blends per group.

${ }^{\mathrm{x}}$ Comparative ratings for each variable among the eight groups are listed as 1 (lower) to 5 (higher) indicating that a majority of the blends within that group fell within the first (lowest) to fifth (highest) range, respectively, of the five 20 -percentile ranges ( 0 th to $<20$ th, 20 th to $<40$ th, 40 th to $<60$ th, 60 th to $<80$ th, 80 th to 100th) calculated for all 127 blends.

${ }^{\mathrm{w}}$ Air space at container capacity.

${ }^{v}$ One or none of the coarser organic substrate components was included in each blend [pine bark (PB), cedar bark (CB), redwood shavings (RS), fine-grade coconut husk chips (CF), medium-grade coconut husk chips (CM)].

"Numbers in parentheses indicate the number of substrate blends among the total number of blends (n) in the respective group.

${ }^{\mathrm{t}}$ All blends with no perlite contained coir.

soil or sand than might typically be used in conventional nursery substrate blends. Some of these blends may not be suitable for general container production purposes. Rather, such blends were included to provide initial data on blends that could be lower in cost and less prone to shrinkage as a result of decomposition of the organic components. Total porosity (air space + container capacity) of the majority of the blends included in this study fell within, or close to, the $50 \%$ to $80 \%$ range recommended by Yeager et al. (2000) for container substrates. Air space for the majority of the blends was also within, or close to, the recommended $10 \%$ to $30 \%$ range; container capacity was within, or lower than, the recommended $45 \%$ to $65 \%$ (by volume) range; and bulk density was within, or above, the recommended 0.19 to $0.70 \mathrm{~g} \cdot \mathrm{cm}^{-3}$ range.

\section{Conclusions}

Results of this study suggest that PCA and CLA can serve as useful exploratory tools in examining similarities and dissimilarities of container substrates, allowing simultaneous consideration of multiple variables and identification of substrate blends with similar characteristics. Selection of substrate blends for nursery production can depend on the specific needs of a particular crop or growing system-blends with greater bulk density to prevent container blow-down in windy conditions, blends with greater container capacity for high water-using crops, blends with greater air space and moderate container capacity for root rot-sensitive crops, or blends with other combinations of characteristics. Variability in the properties of a single substrate component from different sources, or different batches from the same source, must also be taken into consideration. Further studies of this type could include examination of other physical properties such as shrinkage (reduction in volume over time resulting from organic decomposition) and 
chemical properties such as $\mathrm{pH}$ and cation exchange capacity.

\section{Literature Cited}

Abad, M., F. Fornes, C. Carrión, V. Noguera, P. Noguera, A. Maquieira, and R. Puchades. 2005. Physical properties of various coconut coir dusts compared to peat. HortScience 40:2138-2144.

Aldenderfer, M.S. and R.K. Blashfield. 1984 Cluster analysis. Sage Publ., Beverly Hills, Calif.

Bilderback, T.E., W.C. Fonteno, and D.R. Johnson. 1982. Physical properties of media composed of peanut hulls, pine bark, and peatmoss and their effects on azalea growth. J. Amer. Soc. Hort. Sci. 107:522-525.

Bilderback, T.E. and M.R. Lorscheider. 1995. Physical properties of double-processed pine bark: Effects on rooting. Acta Hort. 401:77-83.

Bilderback, T.E., S.L. Warren, J.S. Owen, Jr., and J.P. Albano. 2005. Healthy substrates need physicals too! HortTechnology 15:747-751.

Blashfield, R.K. 1976. Mixture model tests of cluster analysis: Accuracy of four agglomerative hierarchical methods. Psychol. Bull. 83:377-388.

Blythe, E.K., J.L. Sibley, K.M. Tilt, and B. Zinner. 2005. Monolithic slag as a substrate for rooting and bare-rooting stem cuttings. J. Environ. Hort. 23:67-71.

Bredenkamp, G.J., G.K. Theron, and D.R.J. van Vuuren. 1983. Ecological interpretation of plant communities by classification and ordination of quantitative soil characteristics. Bothalia 14:691-699.

Broschat, T.K. 1979. Principal component analysis in horticultural research. HortScience 14:114 117.

Brown, E.F. and F.A. Pokorny. 1975. Physical and chemical properties of media composed of milled pine bark and sand. J. Amer. Soc. Hort. Sci. 100:119-121.
Burés, S., F.X. Martinez, and M. Llorca. 1988. Preliminary study of the application of parametric linear programming in formulation of substrate mixes. Acta Hort. 221:141-152.

Chong, C. 2005. Experiences with wastes and composts in nursery substrates. HortTechnology 15:739-747.

Cole, D.M., J.L. Sibley, E.K. Blythe, D.J. Eakes, and K.M. Tilt. 2005. Effect of cotton gin compost on substrate properties and growth of azalea under differing irrigation regimes in a greenhouse setting. HortTechnology 15: 145-148.

Doi, R. and K. Sakurai. 2004. Principal components derived from soil physico-chemical data explained a land degradation gradient, and suggested the applicability of new indexes for estimation of soil productivity in the Sakaerat Environmental Research Station, Thailand. Intl. J. Sustain. Dev. World Ecol. 11:298-311.

Drogoudi, P.D., C. Tsipouridis, and Z. Michailidis. 2005. Physical and chemical characteristics of pomegranates. HortScience 40:1200-1203.

Gardner, N. and S.C. Hokanson. 2005. Intersimple sequence repeat fingerprinting and genetic variation in a collection of Clematis cultivars and commercial germplasm. HortScience 40:1982-1987.

Goh, K.M. and R.J. Haynes. 1977. Evaluation of potting media for commercial nursery production of container-grown plants. I. Physical and chemical characteristics of soil and soilless media and their constituents. N. Z. J. Agr. Res. 20:363-370.

Haynes, R.J. and K.M. Goh. 1978. Evaluation of potting media for commercial nursery production of container-grown plants. IV. Physical properties of a range of amended peat-based media. N. Z. J. Agr. Res. 21:449-456.

Hernández-Apaolaza, L., A.M. Gascó, J.M. Gascó, and F. Guerrero. 2005. Reuse of waste materials as growing media for ornamental plants. Bioresour. Technol. 96:125-131.

Iezzoni, A.F. and M.P. Pritts. 1991. Applications of principal component analysis to horticultural research. HortScience 26:334-338.
Kuiper, F.K. and L. Fisher. 1975. A Monte Carlo comparison of six clustering procedures. Biometrics 31:777-783.

Kumar, S. and A.K. Sharma. 1993. Cluster analysis of some soils from different regions of north-west India. J. Indian Soc. Soil Sci. 41:598-600.

Lee, J., C.E. Finn, and R.E. Wrolstad. 2004. Anthocyanin pigment and total phenolic content of three Vaccinium species native to the Pacific Northwest of North America. HortScience 39:959-964.

Milks, R.R., W.C. Fonteno, and R.A. Larson. 1989. Hydrology of horticultural substrates: II. Predicting physical properties of media in containers. J. Amer. Soc. Hort. Sci. 114:53-56.

Mojena, R. 1977. Hierarchical grouping methods and stopping rules: An evaluation. Comput. J. 20:359-363.

Rhodes, A.M., S.E. Malo, C.W. Campbell, and S.G. Carmer. 1971. A numerical taxonomic study of the avocado (Persea americana Mill.). J. Amer. Soc. Hort. Sci. 96:391-395.

Sharma, S. 1996. Applied multivariate techniques. John Wiley \& Sons, N.Y.

Shearman, R.C. 1986. Kentucky bluegrass cultivar evapotranspiration rates. HortScience 21:455457.

Suo, Z., W. Li, J. Yao, H. Zhang, Z. Zhang, and D. Zhao. 2005. Applicability of leaf morphology and intersimple sequence repeat markers in classification of tree peony (Paeoniaceae) cultivars. HortScience 40:329-334.

Ward, J.H. 1963. Hierarchical grouping to optimize an objective function. J. Amer. Stat. Assn. 58:236-244.

Wiberg, A., R. Koenig, and T. Cerny-Koenig. 2005. Variability in the physical and chemical properties of retail potting media. HortTechnology 15:752-757.

Yeager, T., C. Gilliam, T. Bilderback, D. Fare, A. Niemiera, and K. Tilt. 2000. Best management practices guide for producing containergrown plants. Southern Nursery Assn, Atlanta, Ga. 